\title{
The monk parakeet (Myiopsitta monachus) as a potential pest for agriculture in the Mediterranean basin
}

\author{
Jorge Castro $\mathbb{D} \cdot$ Carmen Sáez $\cdot$ Mercedes Molina-Morales
}

Received: 23 April 2021 / Accepted: 3 December 2021

(C) The Author(s) 2021

\begin{abstract}
The monk parakeet (Myiopsitta monachus) has been introduced in the last decades to many cities in many parts of the world. For most of this time it has been restricted primarily to urban areas, but it is starting to spread to rural habitats. In its native range, the monk parakeet is considered a pest for agriculture, consuming a wide variety of crops such as grains, fruits, and vegetables. However, there is very little information about its potential role as a pest for agriculture in the areas where it is exotic. Here we conducted an experimental survey of the impact of the monk parakeet on corn in SE Spain using camera traps. The monk parakeet was the animal that produced the highest damage, being responsible for $98.6 \%$ of the time employed by all animals consuming corn. The percentage of cobs damaged ranged from 36.8 to $100 \%$ depending on the cultivar, whereas the crop loss (measured as the length of the cob consumed with respect to the total length of the cob) ranged from
\end{abstract}

Supplementary Information The online version contains supplementary material available at https://doi.org/10.1007/ s10530-021-02702-5.

J. Castro $(\bowtie) \cdot$ C. Sáez

Department of Ecology, University of Granada, Granada, Spain

e-mail: jorge@ugr.es

M. Molina-Morales

Department of Zoology, University of Granada, Granada, Spain
17.7 to $71.1 \%$. The results suggest that the monk parakeet may be a serious pest for agriculture in the Mediterranean basin if their populations continue growing.

Keywords Camera traps - Damage to crops - Exotic species $\cdot$ Invasive species $\cdot$ Maize

\section{Introduction}

The monk parakeet (Myiopsitta monachus) is currently one of the most successful invasive bird species. Native to South America, it has been introduced to four continents (Avery 2020), and its population is growing quickly in many areas, particularly in North America and the Mediterranean basin (Domènech et al. 2003; Strubbe and Matthysen 2009; Postigo et al. 2017; Souviron-Priego et al. 2018). It is considered a pest in its natural range, consuming a wide range of crops producing grains, fruits, and vegetables (Canavelli et al. 2012; Avery 2020). In the areas where it has been introduced, it inhabits mostly cities, feeding on plants from parks and gardens and food supplied by citizens (Sol et al. 1997; Rodríguez-Pastor et al. 2012). However, the species is spreading to rural habitats (e.g., Hernández-Brito et al. 2020), and models predict much higher habitat occupancy in the near future (Muñoz and Real 2006). This raises the 
possibility that it could become a pest for agriculture in the areas where it is exotic. In fact, damage to crops has been reported both in Western Europe and North America (Senar et al. 2016). However, the few studies available to date quantified the amount of food consumed (e.g. Mencheti and Mori 2014; Senar et al. 2016), but without direct observation of the species it is difficult to rule out the possibility that the damage was produced by other species. Thus, precise information regarding the damage produced to crops by the monk parakeet is almost absent despite its potential economic impact.

In this work we conducted an experimental evaluation of damage to different cultivars of maize produced by the monk parakeet by recording videos with camera traps. This provides a more accurate estimate of the impact of the parakeet, as it allows for the detection and clear identification of the animal that produces the damage and its magnitude compared to other potential animals causing damage. Additionally, the damage produced to crops by some animals may boost the damage produced by others in clearing access for the second agent. In such a case, we lack information about how the interaction with other animals might boost the attack to the crops by the monk parakeet, or if on the contrary, the monk parakeet creates an opportunity for crop consumption by other animals. These aspects may be ruled out with direct observation, and the use of camera traps is a particularly suitable approach for this.

\section{Methods}

Study site and natural history of the system

The study was conducted during the summer of 2020 in the Vega de Granada, a flat and irrigated agricultural area of small-sized farms located at ca. $650 \mathrm{~m}$ a.s.l. The entire area is used mainly for crop production, mostly vegetables, maize, tree plantations, and pasture. The soil is deep and loamy, and the climate is Mediterranean-type, with hot, dry summers and mild winters. The mean annual rainfall is $388 \pm 29 \mathrm{~L} \mathrm{~m}^{2} \mathrm{y}^{-1}$ and the mean temperature is $15.3 \pm 0.1{ }^{\circ} \mathrm{C}$ (period 2006-2020). The study was performed in "Huerta de La Paloma" farm (study site hereafter), a private property 1.8 ha in size located in the "Vega de Granada" (SE Spain, 37 $10^{\prime}$ '03.43', N, 3 36' 57.80',
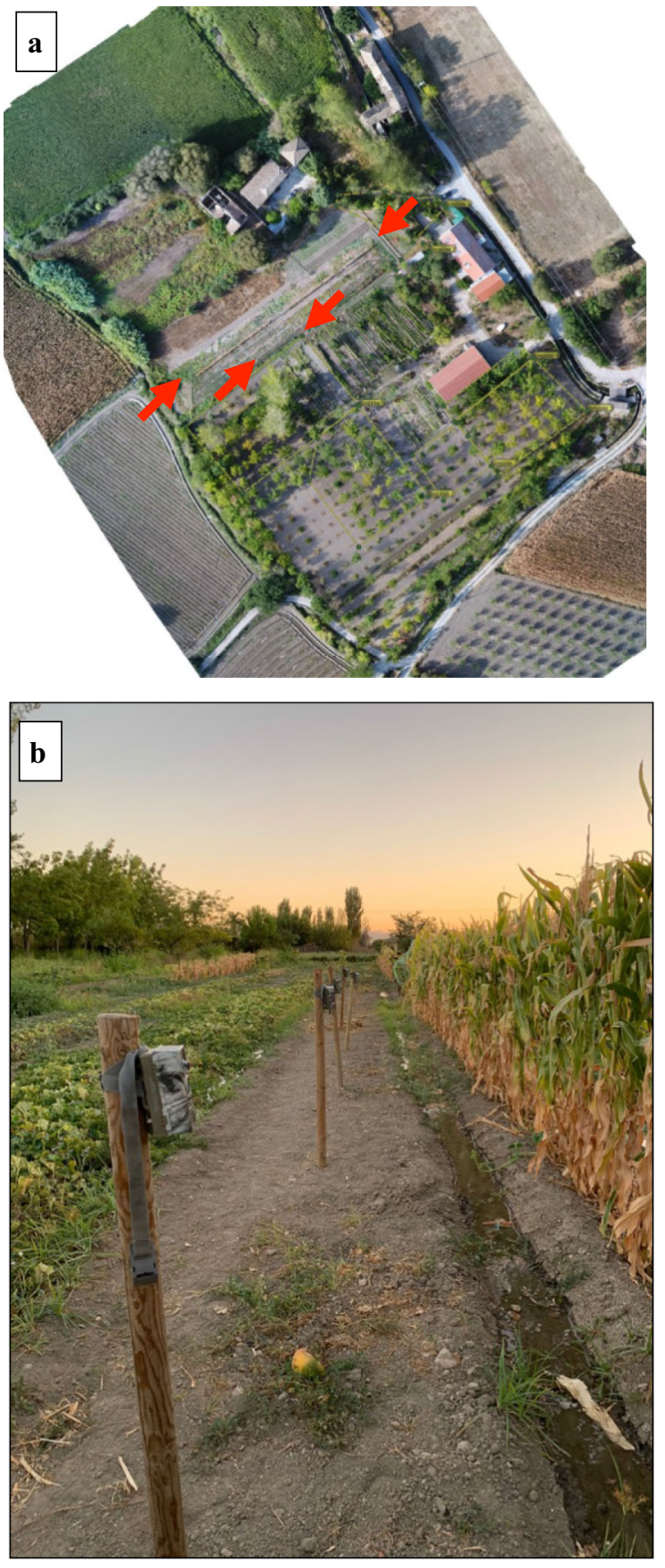

Fig. 1 a Study site ("Huerta de la Paloma" farm) in detail; red arrows show the initial and final points of the furrows of maize used in the study. b Furrows of maize (popcorns red and blue) with camera traps installed at regular intervals on poles $1.5 \mathrm{~m}$ from the plants. Red arrows mark the beginning and the end of the furrows of popcorn (larger line) and Pioneer (shorter line) cultivars. 
Fig. 2 a Detailed image of the Red (left), Blue (middle) and Carrousel (right) cultivars used in the study. b Detailed image of the damage to the cobs of the Pioneer cultivar by the monk parakeet while on the stalk. c The damage to the cobs of Red popcorn in detail.

W). It is at ca. $1 \mathrm{~km}$ from the city of Granada and devoted to research on plant-animal interactions in agroforestry systems and organic production. Different vegetables are planted every year, and ca. $253-6 \mathrm{~m}$ tall scattered fruit trees are dispersed across the farm, including plums, apples, pears, peaches, persimmons, jujube, fig trees, orange trees, and almond trees. There are also well developed edges around the farm and several larger trees such as poplars, walnuts, and Nettle trees (Celtis australis) (Fig. 1a).

The monk parakeet (Myiopsitta monachus) is a non-native species that is spreading in the area. It was first registered in the city of Granada in 1993 (Molina et al. 2016). During the beginning of the XXI century, the number of individuals increased and the monk parakeet started to be a common bird in the area. Currently, there are two colonies in the surroundings of the study site, with a total approximate number of 30 individuals (JC and MMM, personal observation). The number of monk parakeets in the study site (estimated during 10 samplings lasting $30 \mathrm{~min}$ each during the moments of highest animal activity from August 26th to the 1st of October 2020) ranged from 5 to 22 , with an average of $12.2 \pm 1.6$ (sampling done by JC and MMM simultaneously from two different positions on the farm, connected by mobile phones to avoid counting the same individuals twice; birds flying over the study site were not counted). Damage to the crops by the monk parakeet has been observed in the study site and surrounding areas in recent years, although without methodical sampling. In 2019 (one year before this study), a preliminary survey was done by direct observation using binoculars and crop inspection that allowed us to confirm consumption of corn and other crops such as peaches, apples, pears, jujube, and even almond flowers during the blooming season (JC and MMM, personal observation). Based on these observations, in 2020 we planned an experimental sowing to determine the damage produced to maize. This crop was chosen because it is an annual plant (which allowed us to conduct a planned study in
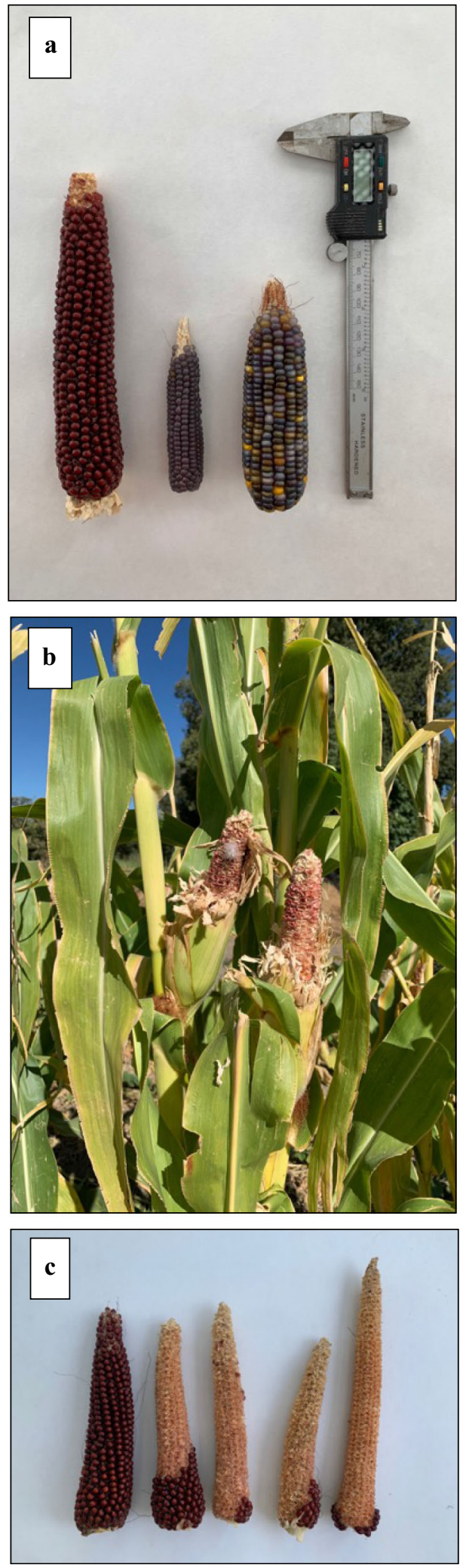
one season) and because it is one of the most common crops in the Vega de Granada.

Experimental design and sampling of animal activity

In April of 2020, two cultivars of popcorn (red and blue popcorn; Fig. 2a) were planted in the study site in two parallel furrows $95 \mathrm{~m}$ in length and separated from each other by $50 \mathrm{~cm}$. Plants within the furrows were sowed in groups of 3-4 seeds (thinned later by 2-3 plants), with a distance between groups of ca. $25 \mathrm{~cm}$. The two cultivars were sowed along the furrows consecutively, each covering a length of $45 \mathrm{~m}$ per furrow and separated from each other by a gap of $5 \mathrm{~m}$ (Fig. 1a). The blue cultivar unexpectedly produced some plants with a larger stalk and ear size (Table 1), and with a kernel color and pattern similar to the carousel popcorn (Fig. 2a). In addition, another furrows $35 \mathrm{~m}$ in length and parallel to the pop corn was planted with a commercial maize commonly grown in the study site (Pioneer ${ }^{\circledR}$ P1524; Pioneer hereafter) at a distance of $15 \mathrm{~m}$ from the popcorn, using the same planting framework as described for the popcorn (Fig. 1a). This produced the following four different corn-type availabilities within the experimental area: (1) Red popcorn, (2) Blue popcorn, (3) Carousel popcorn, and (4) Pioneer. All cultivars were planted the same day and were grown under similar conditions and procedures. The cultivar Pioneer was chosen because it is one of the most commonly used for the production of corn in the area (used to produce food for livestock). The popcorn cultivars are a minority crop in the area compared to Pioneer, but were chosen given the steady recent increase in local organic production as well as for their potential differences in organoleptic properties compared to the corn produced for animal feeding. Plant height, number of cobs per plant, cob diameter and length, and grain mass for all the cultivars is shown in Table 1.

Animal activity in the maize was monitored using video recordings with camera traps. All recordings were taken in summer of 2020 from August 25th to September 20th. For this, wooden poles $6 \mathrm{~cm}$ in diameter and $1.50 \mathrm{~m}$ in height were inserted perpendicularly into the ground at a distance of $1.5 \mathrm{~m}$ from the maize, and camera traps with day and night vision were attached to the poles (Fig. 1b). We used five to eight cameras simultaneously depending on the availability on each particular day, and the recordings covered both daytime and nighttime periods. One camera was a Moultrie Realtree Original, whereas the remaining were Moultrie M-990i models (Moultrie Products, Alabama, USA). Nighttime recordings lasted $30 \mathrm{~s}$ for each video, whereas the daytime recordings lasted $90 \mathrm{~s}$. (except for the Realtree Original, which lasted $60 \mathrm{~s}$ ). The recordings were

Table 1 Characteristics of the cultivars used in the study

\begin{tabular}{|c|c|c|c|c|c|}
\hline Cultivar & $\begin{array}{l}\text { Plant height }{ }^{1} \\
(\mathrm{~cm})\end{array}$ & \# Cobs per plant ${ }^{1}$ & $\begin{array}{l}\text { Cob diameter } \\
(\mathrm{mm})\end{array}$ & $\begin{array}{l}\text { Cob length }{ }^{2} \\
(\mathrm{~cm})\end{array}$ & $\begin{array}{l}\text { Kernel mass } \\
(\mathrm{g}, 10 \text { seeds })\end{array}$ \\
\hline Red popcorn & $\begin{array}{l}170.4 \pm 2.0 \\
(50)\end{array}$ & $\begin{array}{l}1.04 \pm 0.04 \\
(50)\end{array}$ & $\begin{array}{l}23.43 \pm 0.16 \\
(75)\end{array}$ & $\begin{array}{l}18.62 \pm 0.40 \\
(75)\end{array}$ & $1.97 \pm 0.03$ \\
\hline Blue popcorn & $\begin{array}{l}124.4 \pm 1.6 \\
(50)\end{array}$ & $\begin{array}{l}3.46 \pm 0.17 \\
(50)\end{array}$ & $\begin{array}{l}11.61 \pm 0.11 \\
(76)\end{array}$ & $\begin{array}{l}9.55 \pm 0.15 \\
(76)\end{array}$ & $0.69 \pm 0.01$ \\
\hline Carousel popcorn* & $\begin{array}{l}184.4 \pm 5.0 \\
\text { (8) }\end{array}$ & $\begin{array}{l}2.25 \pm 0.31 \\
\text { (8) }\end{array}$ & $\begin{array}{l}20.41 \pm 0.31 \\
(17)\end{array}$ & $\begin{array}{l}16.53 \pm 0.57 \\
(17)\end{array}$ & $2.28 \pm 0.03$ \\
\hline Pioneer & $\begin{array}{l}224.0 \pm 3.4 \\
(30)\end{array}$ & $\begin{array}{l}1.40 \pm 0.09 \\
(30)\end{array}$ & $\begin{array}{l}24.92 \pm 0.38 \\
(41)\end{array}$ & $\begin{array}{l}18.77 \pm 0.41 \\
(41)\end{array}$ & $3.23 \pm 0.03$ \\
\hline
\end{tabular}

In parentheses, sample size used for each variable. (1) Sampled in August 2020 once the stalks reached their maximum size and the kernels were ripening. (2) Sampled in October 2020 after manual harvest (see Sect. 2.3 for further description of the sampling protocol). (*) All available plants were harvested. There were significant differences among cultivars in all the parameters measured (one-way ANOVAs except for kernel mass, that was analyzed with a GLM with an exponential distribution and reciprocal as link function; $p<0.0001$ in all cases) 
taken in 12 batches regularly distributed throughout the sampling period. The cameras were activated simultaneously and recorded for approximately $24 \mathrm{~h}$ per batch in order to collect recordings both during the day and at night. The videos were later revised noting the following variables for each:

1. Species identification and number of individuals per video. For this we considered as individuals any detected animal recorded during the duration of the video, but ensured that a particular individual was not counted more than one time. In cases where we could not guarantee that a new individual was not one that previously left the recording area, it was not added to the final number.

2. Number of individuals that consumed kernels per video, following the same restrictions as described above.

3. Time of consumption; the total time (in seconds) spent by the animals consuming corn. We considered an animal to be consuming corn when it was clearly picking at or plucking kernels and ingesting them (Supplementary Information 1).

\section{Damage to cobs}

The damage to the cobs was sampled on 21st of September once they were dry and ready for harvest. For this, we harvested a random sample of cobs along the whole length of the furrows for each of the cultivars, and we measured the following variables in the laboratory: (1) cob diameter (average of two perpendicular diameters in the central part of the cob), (2) cob length, and (3) length of the portion consumed (Fig. 2c). For the last two variables, we measured the length of the cob that contained grains, not the total length of the cob (this may be larger in cases where some grains at the tip of the cob abort and do not ripen).

\section{Statistical analysis}

The number of individuals per video, the number of individuals consuming corn, and the time of consumption was analyzed on a per-video basis, discarding all the videos that did not record any animal activity. The number of individuals per video and the number of individuals consuming corn per video was analyzed with Generalized Linear Mixed Models
(GLMM) using a Poisson link function, with the species as a fixed factor and day of recording and camera as random factors. To analyze whether consumption time per video varied among species we constructed a Linear Mixed Model (LMM) using the same variables. The significance of the tests was determined using confidence intervals (Gardner and Altman 1986). We compared the previous models with and without random effects using AIC and we found that the most parsimonious was the complex model with the two random factors for all the analyses.

For damage to the cobs, we analyzed two variables: (1) Cobs damaged, the proportion of attacked cobs (a categorical variable, cobs attacked or not attacked); and (2) Crop loss, i.e., the proportion of crop loss estimated as the percentage of cob length consumed (thus a variable that ranged from 0 to $100 \%$ per cob). The percentage of cobs damaged was analyzed with a chi square test. The crop loss was analyzed with a Generalized Linear Model (GLM) using an exponential distribution and a reciprocal link function.

Mixed models were analyzed with $\mathrm{R}$ stats package (version 3.5.1) ( $\mathrm{R}$ Core Team 2018) in RStudio (RStudio Team 2016) and the rest of the analyses were performed with JMP 10.0 software (SAS Institute). Throughout the paper, mean values are followed by standard error (SE).

\section{Results}

Animal activity on maize

A total of 5501 videos were recorded, totaling 446,700 $\mathrm{s}$ of recordings (124.08 h). Of those, 4936 videos were recorded in daylight $(429,750 \mathrm{~s}$ of recording) and 565 during night (16,950 $\mathrm{s}$ of recording). Not a single vertebrate was recorded during night hours, and therefore this period is not considered further. For the daytime period, $49.6 \%$ of the time recorded was in the Red cultivar, $34.0 \%$ in the Blue cultivar (pooling both Blue and the intermingled Carousel plants), and $16.4 \%$ in the Pioneer cultivar. A large fraction of the videos (4882 out of the 5501 recorded) were triggered due to the movement of the leaves in the wind but recorded no animals (daylight and night pooled).

A total of 5 vertebrate species were recorded foraging on the maize plants, all of them birds (Table 2). Of those, the monk parakeet, house sparrow 
Table 2 Summary of overall values (data from all videos pooled) and values on a per video basis (data used for statistical analyses; see Table 3)

\begin{tabular}{|c|c|c|c|c|c|}
\hline Data set & Variable & $\begin{array}{l}\text { Monk } \\
\text { parakeet }\end{array}$ & $\begin{array}{l}\text { House } \\
\text { sparrow }\end{array}$ & Pigeon & Eurasian magpie \\
\hline \multirow{4}{*}{$\begin{array}{l}\text { Overall } \\
\text { values }\end{array}$} & Number of videos recording the species & 477 & 189 & 22 & 8 \\
\hline & Total number of individuals detected & 1380 & 337 & 23 & 9 \\
\hline & Total number of individuals consuming corn & 1041 & 10 & 13 & 6 \\
\hline & Total time consuming corn (in seconds) & 61937 & 77 & 595 & 210 \\
\hline Per video & Individuals per video (mean $\pm \mathrm{SE}$ ) & $\begin{array}{l}2.89 \pm 0.09 \\
(1-11)\end{array}$ & $\begin{array}{l}1.78 \pm 0.08 \\
(1-6)\end{array}$ & $\begin{array}{l}1.04 \pm 0.04 \\
(1-2)\end{array}$ & $1.12 \pm 0.12(1-2)$ \\
\hline \multirow[t]{2}{*}{ basis } & Individuals consuming kernels per video (mean $\pm \mathrm{SE}$ ) & $\begin{array}{l}2.18 \pm 0.07 \\
(1-9)\end{array}$ & $\begin{array}{l}0.05 \pm 0.02 \\
\quad(1)\end{array}$ & $\begin{array}{l}0.59 \pm 0.02 \\
(1-2)\end{array}$ & $0.75 \pm 0.25(1-2)$ \\
\hline & $\begin{array}{l}\text { Duration of consumption per video (mean } \pm \mathrm{SE} \text {; in } \\
\text { seconds) }\end{array}$ & $\begin{array}{l}129.8 \pm 4.8 \\
(1-549)\end{array}$ & $\begin{array}{l}0.4 \pm 0.2 \\
(1-25)\end{array}$ & $\begin{array}{l}27.1 \pm 7.9 \\
(1-90)\end{array}$ & $\begin{array}{l}26.2 \pm 10.6 \\
(34-72)\end{array}$ \\
\hline
\end{tabular}

Note that for overall values, "individuals" does not refer to the real number of individuals, but to the summatory of different individuals that were recorded in each video, ensuring that individuals were not double-counted during the duration of the video (see Section 2.2 for further explanations)

(Passer domesticus), common wood pigeon (Columba palumbus), and Eurasian magpie (Pica pica) were recorded consuming corn. A blackbird (Turdus merula) was recorded only once, but without consumption of corn. The monk parakeet was the species most frequently observed (79\% of the individuals recorded), the species with most individuals detected consuming corn ( $97.3 \%$ of the cases), and the species that spent the most time consuming corn $(98.6 \%$ of the time that any animal was recorded consuming corn; Tables 2 and 3). The activity of the monk parakeet peaked during the early morning hours and was virtually absent from noon to early afternoon (Fig. 3).

Damage to the cobs

The percentage of cobs damaged differed among cultivars (Chi square $=70.62$, d.f. $=3, p<0.0001$ ), being $90.7 \%$ for the Red cultivar, $36.8 \%$ for the Blue cultivar, $48.8 \%$ for Pioneer, and $100 \%$ for the Carousel cultivar. The crop loss also differed among cultivars (L-R chi square $=95.14$; d.f. $=3 ; p<0.0001)$, being $71.1 \pm 3.5 \%$ for the Red cultivar, $17.7 \pm 3.3 \%$ for Blue cultivar, $17.7 \pm 3.4 \%$ for Pioneer, and $65.1 \pm$ $7.1 \%$ for the Carousel cultivar.

\section{Discussion}

The use of camera traps has allowed for precise identification of the agents that cause damage in maize in the study area. Some consumption of cobs occurred in the study area before the arrival of the parakeets, and local farmers typically attribute this to rats (JC, personal communication). Other bird species such as pigeons and house sparrows also perch on the maize plants, but their potential role as a pest for the crop was unknown. Our results document with high precision that, according to our data, all of these animals are irrelevant compared with the damage produced by the monk parakeet, which was responsible for more than $98 \%$ of the time spent consuming corn. Moreover, the feeding behavior of the parakeet is particularly voracious (Supplementary Information 1), and it is very likely that the amount of kernels ingested by this bird in relation to other species is even above the percentage of time consuming corn registered. In this sense, it is particularly remarkable that the foraging of the house sparrow seemed entirely linked to the previous activity of the parakeets: once the parakeet opened the leaves of the cob and started to consume it, this created an opportunity for the attack by the sparrows, which otherwise could not feed on the grains. Thus, although the magnitude of damage 
The monk parakeet (Myiopsitta monachus) as a potential pest for agriculture in the...

Table 3 Summary of the statistical analyses (Generalized Linear Mixed Models and Linear Mixed Model) for data on a per video basis (i.e. using videos as the sampling unit)

\begin{tabular}{|c|c|c|c|c|c|c|c|}
\hline \multicolumn{8}{|l|}{ Variable } \\
\hline \multirow[t]{8}{*}{ Individuals per video } & \multicolumn{5}{|c|}{ Random effect } & Variance & SD \\
\hline & \multicolumn{5}{|l|}{ Day } & 0.06 & 0.24 \\
\hline & \multicolumn{5}{|l|}{ Site } & 0.03 & 0.17 \\
\hline & \multicolumn{2}{|c|}{ Fixed Factor } & \multicolumn{3}{|c|}{ Estimate (SE) } & Lower CI & Upper CI \\
\hline & \multicolumn{2}{|c|}{ Intercept } & \multicolumn{3}{|c|}{$1.02(0.09)$} & 0.82 & 1.21 \\
\hline & \multicolumn{2}{|c|}{ Pigeon } & \multicolumn{3}{|c|}{$-1.26(0.21)$} & -1.71 & $-0.86^{*}$ \\
\hline & \multicolumn{2}{|l|}{ Magpie } & \multicolumn{3}{|c|}{$-0.65(0.34)$} & -1.39 & $-0.04^{*}$ \\
\hline & \multicolumn{2}{|l|}{ Sparrow } & \multicolumn{3}{|c|}{$-0.46(0.06)$} & -0.58 & $-0.33^{*}$ \\
\hline \multirow{8}{*}{\multicolumn{2}{|c|}{$\begin{array}{l}\text { Individuals consuming kernels per } \\
\text { video }\end{array}$}} & \multicolumn{4}{|c|}{$\begin{array}{l}\text { Random } \\
\text { effect }\end{array}$} & Variance & SD \\
\hline & & \multicolumn{4}{|c|}{ Day } & 0.09 & 0.30 \\
\hline & & \multicolumn{3}{|c|}{ Site } & & 0.05 & 0.23 \\
\hline & & \multicolumn{3}{|c|}{ Fixed Factor } & $\begin{array}{l}\text { Estimate } \\
\text { (SE) }\end{array}$ & $\begin{array}{l}\text { Lower } \\
\text { CI }\end{array}$ & $\begin{array}{l}\text { Upper } \\
\text { CI }\end{array}$ \\
\hline & & \multicolumn{3}{|c|}{ Intercept } & $0.68(0.12)$ & 0.41 & 0.93 \\
\hline & & \multicolumn{3}{|c|}{ Pigeon } & $-1.58(0.28)$ & -2.20 & $-1.07 *$ \\
\hline & & \multicolumn{3}{|c|}{ Magpie } & $-0.73(0.42)$ & -1.67 & 0.0004 \\
\hline & & \multicolumn{3}{|c|}{ Sparrow } & $-3.67(0.32)$ & -4.37 & $-3.11^{*}$ \\
\hline \multirow{8}{*}{\multicolumn{2}{|c|}{ Duration of consumption per video }} & Ranc & ffect & & & Variance & SD \\
\hline & & Day & & & & 726.2 & 26.95 \\
\hline & & Site & & & & 360.8 & 19.00 \\
\hline & & Fixed & tor & & timate (SE) & Lower CI & Upper CI \\
\hline & & Inter & & & $0.78(10.78)$ & 98.26 & 142.10 \\
\hline & & Pigec & & & $122.68(19.28)$ & -160.32 & $-83.42 *$ \\
\hline & & Mag & & & 78.02 (30.97) & -139.52 & $-17.66^{*}$ \\
\hline & & Sparı & & & $125.66(7.6)$ & -140.81 & $-110.87^{*}$ \\
\hline
\end{tabular}

See lower part of Table 2 for mean values of each variable. *Significant differences between the species and the reference level (monk parakeet). Confidence interval (Lower CI $2.5 \%$ and Upper CI $97.5 \%$ ) is used to estimate significance. Magpie = Eurasian magpie; Sparrow $=$ house sparrow produced by the house sparrow is small, it is likely that its impact is the result of a facilitative interaction mediated by the parakeet.

The damage produced by the monk parakeet was particularly high for some of the cultivars, with Red and Carousel popcorns reaching values above $70 \%$ of the crop loss. This implies the virtual destruction of the crop from an agronomic and economic point of view. On the other hand, the damage differed substantially among cultivars. A potential reason could be the size of the plant, the cob, or the kernel, which might explain the lowest values for the smallest plants (Blue cultivar). However, all of these parameters were highest in the Pioneer cultivar, which nonetheless suffered less attacks than the Red or the Carousel popcorn. It is therefore very likely that the parakeets chose the cultivars according to organoleptic properties apart from their sizes. On the other hand, it is remarkable that popcorn suffered the highest damage, contrary to the results reported by Senar et al. (2016) where the parakeets damaged commercial maize but not popcorn.

The results relating to damage must be taken with caution given that our sampling was done in a smallscale experimental set-up where maize formed three furrows. It is not uncommon that damage caused by vertebrates (including the monk parakeet) is higher in the outer furrows than in the interior of the fields (Canavelli et al. 2012; Senar et al. 2016). In this sense, in a previous study, Senar et al (2016) documented a 


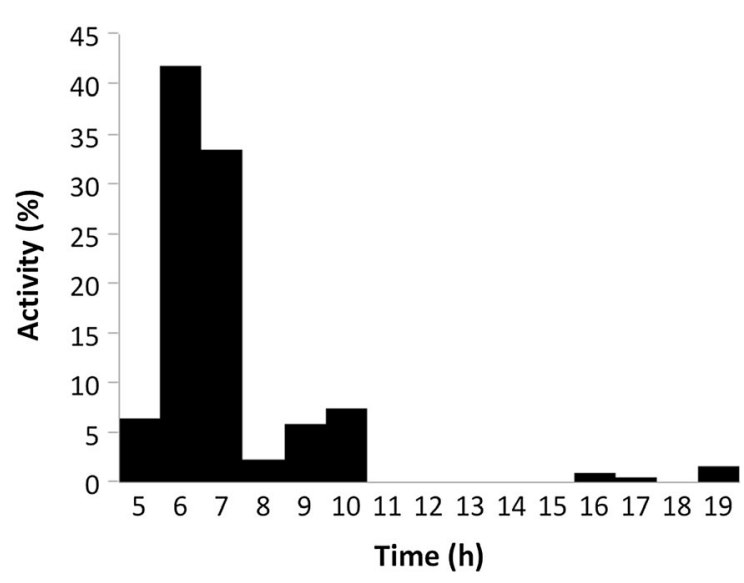

Fig. 3 Daily pattern of activity of the monk parakeet on maize (hours according to solar time). The pattern is similar across cultivars; data from all cultivars have been pooled for representation.

value of $28 \%$ of cobs damaged in larger fields of commercial maize in NE Spain, which is below the $48 \%$ that we found in our study area for Pioneer (although still significant damage). The greater damage observed in this study may also be related to other factors such as the landscape configuration in the study area or the proximity to urban areas. It has been suggested that the monk parakeet takes advantage of the conditions provided by cities (e.g., food supply, microclimatic conditions, or predation release) to establish itself and proliferate, but their spread to rural areas may be limited through biotic resistance (i.e., competition and predation; see Hernández-Brito et al. 2020). In our case, the study area is composed of a network of urban areas (villages among a metropolitan area that may provide safe sites for the parakeet) within a matrix of agricultural land where the parakeet can forage and feed during the day. Whether the results of our study can be extrapolated to other regions of the Mediterranean basin or are specific to the study area is a matter that needs further research. Nonetheless, we should consider that the monk parakeet is also spreading to rural habitats in other areas of the Mediterranean basin (Postigo et al. 2017; Hernández-Brito et al. 2020) and that models predict the potential for much higher habitat occupancy (Muñoz and Real 2006). In addition, its population is growing exponentially in many cities of the Mediterranean basin (Domènech et al. 2003; Postigo et al. 2017, 2019; Souviron-Priego et al. 2018). It is also notable that the damage in our study was produced by a small number of birds, as the estimated population utilizing the study site was below 22 individuals. Moreover, the warm climatic conditions of the Mediterranean basin, the large proportion of croplands in the territory, and the dietary opportunism of the monk parakeets may favor their spread (Strubbe and Matthysen 2009; Bucher and Aramburú 2014; Postigo et al. 2019). Under these circumstances, there is a strong possibility that the species may become a serious pest for agriculture in the Mediterranean basin if it reaches the lag phase in the invasion process.

Acknowledgements This work was supported by the Spanish Ministerio de Ciencia e Innovación (Project PID2019106806GB-I00) and Juan de la Cierva-Incorporación (IJC2018-036411-I).

Author's contribution JC and MMM conceived the idea and conducted the video-recordings. CS visualized the videos and extracted the data. JC and MMM analyzed the data and wrote the first draft of the ms. All authors reviewed and approved the ms.

Funding Funding for open access charge: Universidad de Granada / CBUA.

Open Access This article is licensed under a Creative Commons Attribution 4.0 International License, which permits use, sharing, adaptation, distribution and reproduction in any medium or format, as long as you give appropriate credit to the original author(s) and the source, provide a link to the Creative Commons licence, and indicate if changes were made. The images or other third party material in this article are included in the article's Creative Commons licence, unless indicated otherwise in a credit line to the material. If material is not included in the article's Creative Commons licence and your intended use is not permitted by statutory regulation or exceeds the permitted use, you will need to obtain permission directly from the copyright holder. To view a copy of this licence, visit http://creativecommons.org/licenses/by/4.0/.

Data availability statement The datasets generated during the current study and the video-recordings are available from the corresponding author on reasonable request.

\section{References}

Avery ML (2020) Monk parakeet (Myiopsitta monachus Boddaert, 1783). In: Downs CT, Hart LA (eds) Invasive birds: global trends and impacts. CAB International, Wallingford, pp 76-84

Bucher EH, Aramburú RM (2014) Land-use changes and monk parakeet expansion in the Pampas grasslands of Argentina. J Biogeography 41:1160-1170

Canavelli SB, Aramburú R, Zaccagnini ME (2012) Aspectos a considerar para disminuir los conflictos originados por los 
daños de la cotorra (Myiopsitta monachus) en cultivos agrícolas. Hornero 27:89-101

Domènech J, Carrillo J, Senar JC (2003) Population size of the monk parakeet Myiopsitta monachus in Catalonia. Rev Catalana d'Ornitologia 20:1-9

Foundation for Statistical Computing, Vienna, Austria. https:// www.R-project.org/.

Gardner MJ, Altman DG (1986) Confidence intervals rather than P values: estimation rather than hypothesis testing. $\mathrm{Br}$ Med J 292:746-750

Hernández-Brito D, Blanco G, Tella JL, Carrete M (2020) A protective nesting association with native species counteract biotic resistance for the spread of an invasive parakeet from urban into rural habitats. Front Zool 17:13. https://doi.org/10.1186/s12983-020-00360-2

Menchetti M, Mori E (2014) Worldwide impact of alien parrots (Aves Psittaciformes) on native biodiversity and environment: a review. Ethol Ecol Evol 26:172-194

Molina B, Postigo JL, Muñoz AR, Del Moral JC (eds) (2016) La cotorra argentina en España, población reproductora en 2015 y método de censo. SEO/BirdLife, Madrid

Muñoz AR, Real R (2006) Assessing the potential range expansion of the exotic monk parakeet in Spain. Divers Distrib 12:656-665

Postigo JL, Shwartz A, Strubbe D, Muñoz A-R (2017) Unrelenting spread of the alien monk parakeet Myiopsitta monachus in Israel. Is it time to sound the alarm? Pest Manag Sci 73:349-353

Postigo JL, Strubbe D, Mori E, Ancillotto L, Carneiro I, Latsoudis P, Menchetti M, Pârâu LG, Parrott D, Reino L, Weiserbs A, Senar JC (2019) Mediterranean versus
Atlantic monk parakeets Myiopsitta monachus: towards differentiated management at the European scale. Pest Manag Sci 75:915-922

R Core Team (2018) R: A language and environment for statistical computing. $\mathrm{R}$

RStudio Team (2016) RStudio: Integrated Development for R. RStudio, Inc., Boston, MA. http://www.rstudio.com/

Rodríguez-Pastor R, Senar JC, Ortega A, Faus J, Uribe F, Montalvo T (2012) Distribution patterns of invasive Monk parakeets (Myiopsitta monachus) in an urban habitat. Anim Biodivers Conserv 35:107-117

Senar JC, Domènech J, Arroyo L, Torre I, Gordo O (2016) An evaluation of monk parakeet damage to crops in the metropolitan area of Barcelona. Anim Biodivers Conserv 39:141-145

Sol D, Santos DM, Feria E, Clavell J (1997) Habitat selection by the monk parakeet during colonization of a new area in Spain. Condor 99:39-46

Souviron-Priego L, Muñoz AR, Olivero J, Vargas JM, Fa JE (2018) The legal international wildlife trade favours invasive species establishment: the monk and ring-necked parakeets in Spain. Ardeola 65:233-246

Strubbe D, Matthysen E (2009) Establishment success of invasive ring-necked and monk parakeets in Europe. J Biogeogr 36:2264-2278

Publisher's Note Springer Nature remains neutral with regard to jurisdictional claims in published maps and institutional affiliations. 